\title{
BMJ Open Preparing Chinese patients with comorbid heart disease and diabetes for home management: a mixed methods study
}

\author{
Xian-Liang Liu, ${ }^{1,2,3,4}$ Karen Willis, ${ }^{5,6}$ Chiung-Jung (Jo) Wu, ${ }^{\oplus, 8,9}$ Paul Fulbrook, ${ }^{2,10,11}$ \\ Yan Shi, ${ }^{3}$ Maree Johnson ${ }^{12,13}$
}

To cite: Liu X-L, Willis K, Wu C-J(Jo), et al. Preparing Chinese patients with comorbid heart disease and diabetes for home management: a mixed methods study. BMJ Open 2019;9:e029816. doi:10.1136/ bmjopen-2019-029816

- Prepublication history and additional material for this paper are available online. To view these files, please visit the journal online (http://dx.doi. org/10.1136/bmjopen-2019029816).

Received 13 February 2019 Revised 01 August 2019 Accepted 19 August 2019

\section{Check for updates}

(C) Author(s) (or their employer(s)) 2019. Re-use permitted under CC BY-NC. No commercial re-use. See rights and permissions. Published by BMJ.

For numbered affiliations see end of article.

\section{Correspondence to}

Xian-Liang Liu;

liu.xianliang@myacu.edu.au

Professor Yan Shi; shlzk2002@163.com

\section{ABSTRACT}

Objective To explore how health education received by patients with acute coronary syndrome (ACS) and type 2 diabetes mellitus (T2DM) influences patients' self-efficacy and self-management and changes in behaviour at, and following, hospital discharge.

Design This study used a convergent mixed methods design.

Participants Twenty-one participants with completed surveys and interviews at discharge and home follow-up were included in the analysis.

Setting At a coronary care unit of a major hospital in Shanghai, China.

Results Most participants ( $\mathrm{n}=17)$ did not perceive they had sufficient education or ability to manage both conditions. More concerning was that most participants $(n=16)$ reported low self-efficacy in the management of ACS symptoms. Three major themes were identified: self-management of ACS and T2DM represents a complex interplay between individual self-efficacy, knowledge and skills, as individuals navigate shifting self-management priorities due to perceived condition severity; the social environment is integral to lifestyle and behaviour change and managing multiple health conditions requires body and mind systems' harmony.

Conclusions The inpatient education received did not enhance participants' confidence to manage either condition on discharge. While an unhealthy lifestyle was embedded within social roles and norms, some social activities, such as square dancing, positively influenced health behaviour. Culturally appropriate education for Chinese people with diabetes and ACS should contain information on maintaining mind and body harmony. Family members should be involved in formal education.

\section{INTRODUCTION}

Patients presenting with multiple chronic conditions are frequently encountered within clinical practice, often experiencing poorer health outcomes than those with a single condition. ${ }^{1}$ Acute coronary syndrome (ACS) and type 2 diabetes mellitus (T2DM) often present as comorbid diseases that require coordinated management and health

\section{Strengths and limitations of this study}

- Within China, this is the first mixed methods study to examine the impact and the experiences of health education received by patients with comorbid acute coronary syndrome and type 2 diabetes mellitus.

- Within this unique setting, the findings of this study inform recommendations for the design of health education for Chinese patients with multiple health conditions, nuanced to their unique cultural context and values.

- The use of both qualitative and quantitative methods facilitated an exploration of patients' perceptions of their abilities and management behaviours. By connecting elements of survey and clinical outcomes data (quantitative) with interview data (qualitative) at two time points, a richer understanding of how behaviours (risk factors) change from hospital to community was uncovered.

- The study was conducted at a major hospital in Shanghai and represents a small number of mainly male participants. The findings may therefore be transferable to other similar settings or conditions but are not generalisable to the population in the positivist sense. Further research on women with acute coronary syndrome and type 2 diabetes mellitus is recommended.

education. ${ }^{23}$ Comorbidities have a significant impact on treatment regimens and self-management. Patients with both ACS and T2DM prioritise self-management of the more seriously perceived comorbid condition, and the self-management and recovery trajectory is a complex process for patients with both diseases. ${ }^{23}$

The prevalence of T2DM in patients with ACS ranges from one in four ${ }^{4}$ to more than $50 \% .^{5}$ Globally, patients with ACS and diabetes have more severe types of coronary lesions compared with those without diabetes. ${ }^{6}$ Mortality for patients with ST segment elevation myocardial infarction 
(STEMI) and diabetes was significantly higher compared with those experiencing STEMI only (8.5\% vs $5.4 \%){ }^{7}$ Moreover, patients with ACS and diabetes have a $50 \%$ increase in long-term mortality compared with patients with ACS without diabetes. ${ }^{8}$

ACS and T2DM are often associated with similar or related risk factors including low physical activity, obesity, smoking and high sugar and fat intake. ${ }^{9}$ However, patients with both ACS and T2DM report difficulty and confusion integrating lifestyle changes and treatment regimes. ${ }^{2}{ }^{3}$ Health education is established as an essential component in the treatment of patients with ACS and T2DM with goals focusing on transforming risk factors by developing a healthy lifestyle, combined with self-management to achieve targeted clinical outcomes. ${ }^{10}$ Education programmes for patients with ACS and T2DM attempt to increase patients' confidence and management skills rather than simply educating them about the disease process and value of healthy living. ${ }^{3}$

Social cognitive theory emphasises the importance of developing patient self-efficacy by supporting and sustaining self-management of chronic conditions. ${ }^{12}$ Self-efficacy, or an individual's belief in their potential ability to manage their symptoms, can motivate them to overcome barriers to behavioural change. ${ }^{13}$ Higher levels of self-efficacy are associated with better attendance in cardiac rehabilitation, ${ }^{14}$ increased maintenance of medication, diet and physical activity regimes. ${ }^{15} 16$ Perceived self-efficacy is also a predictor of future health status. ${ }^{15}{ }^{16}$ Furthermore, self-efficacy and self-management behaviour also directly impact glycaemic regulation among patients with T2DM. ${ }^{17}$

However, low self-efficacy and multiple health conditions have been found to be barriers for active self-management or accessing self-management support resources. ${ }^{18}$ This is particularly relevant to patients with ACS and T2DM, as previous research has identified concerns with self-efficacy and confidence to perform self-management behaviours. ${ }^{19}$ Patients may also experience a sense of hopelessness and fatigue after an ACS event, ${ }^{19}$ further exacerbating their ability to self-manage.

Self-management is a common construct in patient education settings and refers to patient engagement in activities related to medical regimen adherence, symptom monitoring, psychosocial regulation and lifestyle change. ${ }^{20}$ The successful self-manager takes responsibility, is knowledgeable and active in using knowledge to make decisions related to their health..$^{212}$ For patients experiencing comorbid disease, the barriers to self-management include lack of knowledge, poor access to care and inadequate contact with health professionals, ${ }^{23}$ as well as low self-efficacy and lack of social support. ${ }^{24}$

Diabetes self-management education and support is proposed as the cornerstone of care and management for all people with diabetes and is necessary to prevent or delay complications. ${ }^{25}$ Similarly, patients with ACS also require support during their cardiac rehabilitation and recovery period, particularly when discharged from the hospital. ${ }^{26}$ Earlier pilot studies suggest that cardiac-diabetes self-management programmes may improve knowledge, self-efficacy and self-management behaviours among patients with T2DM following an ACS event, ${ }^{27} 28$ but further research is required.

The challenge for individuals to manage two or more diseases is substantial ${ }^{23}$ and may require a re-evaluation of their disease care goals and self-management needs. ${ }^{2}$ Lifestyle guidelines and recommendations provided to patients with T2DM following an ACS event are often presented separately for each disease and not tailored to comorbid disease. ${ }^{29}$ When discharged from the hospital, this can cause confusion and uncertainty regarding disease management priorities and strategies for patients with comorbid disease. ${ }^{23}$

Within China, health education is provided principally during the hospital admission with limited support provided within the community. Currently, health education provided to patients presenting with ACS and T2DM focuses on prescribed topics that reflect the content specified by current Chinese guidelines. ${ }^{30}$ However, there has been little research investigating patients' experience from the hospital into the community and little is known about the influence of health education on self-efficacy and self-management of patients with these comorbidities. $^{3}$

\section{Aim}

The aim of the study was to explore patients' perceptions of their abilities to manage (quantitative data on self-efficacy, health behaviours, clinical outcomes; qualitative interviews about risk management behaviours) their comorbid conditions as they experienced education and recovery and then returned to their homes and communities (qualitative interviews in community). The focus on perceptions of abilities to manage aspects of their conditions combined with the need to develop or maintain key health behaviours critical to both conditions were explored and expanded on, with the use of a mixed methods approach.

\section{METHODS}

\section{Study design}

A convergent mixed methods design ${ }^{31} 32$ was used, with data being collected at a similar time point (see figure 1). Aspects of the survey (quantitative) relating to specific health behaviours such as diet regulation, medical treatment and physical exercise influenced the questions posed in interviews (also relating to health behaviours, diet regulation, medical treatment and physical exercise) (qualitative). The quantitative data (survey and patient healthcare record review) were initially analysed and reported on separately ${ }^{33}$ and then the integration of aspects of survey and patient healthcare record (involving coding of data into further classifications of groups) with the textual data of the interviews, ${ }^{34}$ supported the development of meta-inferences. Weighting of data, in this 


\section{Quantitative Component (Quant)}

One day before discharge:

(1) Survey (including three standardized scales) at hospital

After discharge:

(2) Patient healthcare record review

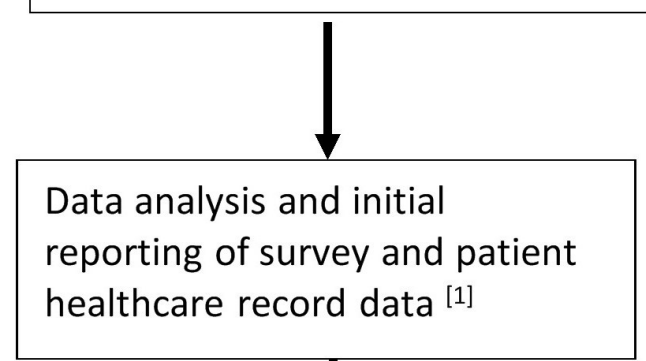

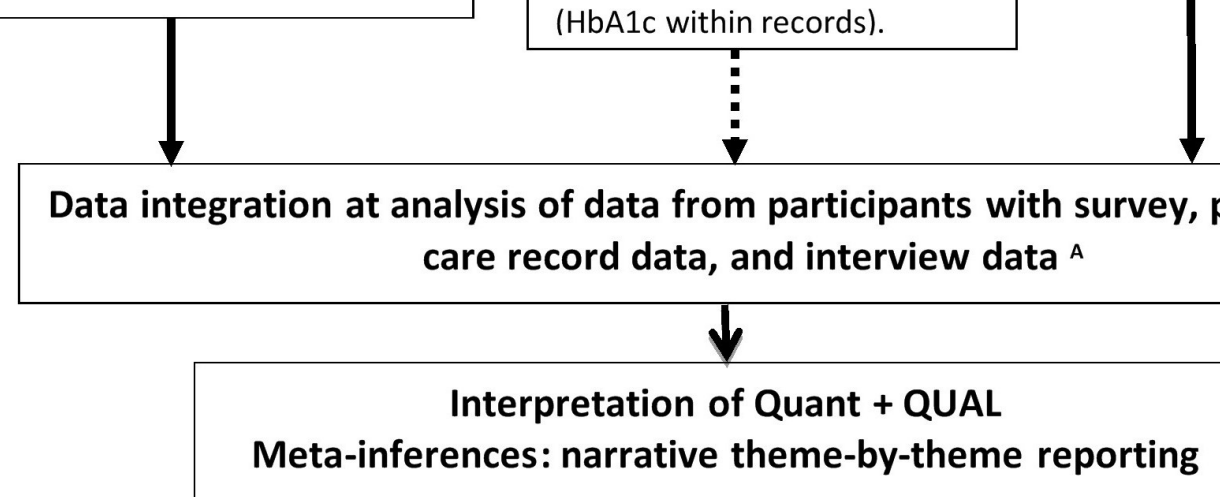

Figure 1 Flowchart of the implementation of a convergent mixed methods design for this study. Adapted from: Lewis, J. (2011). Mixed methods research. In S. Jirojwong, M. Johnson, \& A. Welch (Eds.), Research methods in nursing and midwifery: Pathways to evidence-based practice (pp. 268-285). Oxford: Oxford University Press. Reference [1]: Liu, X. L., Wu, C. J., Willis, K., Shi, Y., \& Johnson, M. The impact of inpatient education on self-management for patients with acute coronary syndrome and type 2 diabetes mellitus: a cross-sectional study in China. Health Educ Res. 2018;33(5):389-401. doi: 10.1093/her/cyy023. A: Analysis conducted using NVivo Matrix and Query function bringing three data sets together. QUAL, qualitative study; Quant, quantitative; VAS, visual analogue scale.

presentation of the findings, was towards the qualitative data, not previously reported (see figure 1).

A convenience sample of patients with ACS and T2DM, reflecting the same participants on quantitative measures of behaviour, with their interview data on discharge from hospital and up to 4 weeks following discharge, provided a unique perspective of these individuals transitioning from hospital, where behaviours can be well controlled (eg, diet, medication), to uncontrolled environments within the participants' homes and local communities where healthy behaviours can be challenged. This mixed methods approach has provided an opportunity to examine how changes in behaviours are initiated and sustained into the community (qualitative element) within a background of quantifiable data on perceptions of education received, ability to self-manage and clinical outcomes.

This research was approved by the Human Research Ethics Committee (HREC), Australian Catholic University (2016-148R) and the HREC, Tenth People's Hospital of Tongji University (SHSY-IEC-3.0/16-20/01) and was conducted in accordance with ethical principles set out in the Helsinki Declaration. ${ }^{35}$

\section{Setting and sample}

The study was conducted at a major hospital in Shanghai, China. The inclusion criteria were: index diagnosis of ACS and T2DM, over 18 years of age and able to understand, speak and write Mandarin Chinese. Patients with severe debilitating medical or related conditions, for example physician-diagnosed persistent muscle spasms, cognitive problems or severe mental illness were excluded. Initially, the survey reported in this study was sent to a non-probability sample of participants. An item in the survey asked participants if they were interested in being interviewed on discharge and up to 4 weeks after discharge from the hospital. 166 patients with ACS and T2DM were invited and 160 patients (160/166, 96.39\%) were willing to participate in the survey. For the qualitative component, it was expected that a sample of between 
20 and 30 participants would be required. ${ }^{31}{ }^{32}$ Of the 160 respondents who completed the survey, 68 participants were asked if they were interested in being interviewed at two later time points and a convenience sample of 21 participants consented to be interviewed. The findings from this subset are reported here.

\section{Data sources}

Surveys

Within the survey, perceptions of education that had been received were measured using a visual analogue scale (VAS) ranging from 1 (little or no education) to 100 (comprehensive education). Diabetes knowledge was measured using the Chinese version of Diabetes Knowledge Scale (C-DKS) $;^{36}$ self-efficacy was measured using the Chinese versions of the Acute Coronary Syndrome Response Index (C-ACSRI) (attitudes subscale only) ${ }^{37}$ and the Diabetes Management Self-Efficacy Scale (C-DMSES). The C-DMSES included items about self-management and behavioural changes, such as blood sugar monitoring, regular foot inspection, diet regulation, medical treatment, physical exercise and weight management. ${ }^{38}$ All scales demonstrate satisfactory reliability and validity. ${ }^{36-38}$

\section{Interviews}

The interviews were conducted using semistructured schedules (see online supplementary appendices 1 and 2) to ensure participants' focus on perceptions of the education they had received, their understanding of their conditions and management and their perceptions of actual or expected behavioural change associated with their comorbid disease. The telephone interview focused on how participants were managing their health conditions at home.

\section{Patient healthcare record review}

A patient healthcare record review tool (including patient demographics, admission history, admission diagnosis, physical examinations, laboratory tests and treatment) was developed to assist data collection after participants were discharged from the hospital. Inter-rater reliability was satisfactory and is described in detail elsewhere. ${ }^{33}$

\section{Procedures}

Following initial consent, participants were invited to complete the self-administered survey, which was administered 1 day before hospital discharge. An item in the survey asked participants to express interest to be interviewed for the study. If so, they were invited to participate in a semistructured interview conducted prior to discharge, followed by a telephone interview up to 4 weeks later.

Initial interviews were conducted at a mutually agreeable location within the hospital and ranged from 16 to 47 $\mathrm{min}$. The follow-up telephone interviews were somewhat shorter (range 4-22 min). All interviews were conducted by a male registered nurse researcher, fluent in Mandarin Chinese. They were digitally audio recorded and transcribed verbatim.

\section{Data analysis}

Quantitative data were analysed using the Statistical Package for the Social Sciences (SPSS) V.22. Descriptive statistics were used to describe demographic variables and responses on different scales. A cut-off point of $50^{3940}$ on the VAS for health education was used to classify participants as having received limited $(\leq 50)$ or sufficient $(>50)$ education. A cut-off point of $4^{3940}$ was used to classify participants with inadequate $(\leq 4)$ or adequate $(>4)$ diabetes knowledge (range 0-8). These cut-off points were informed by research using similar instruments in other samples. 3940

For the purposes of providing meaningful groups for data integration, participants were classified in terms of high $(\geq 15)$ or low $(<15)$ level $^{41}$ ACS symptom management self-efficacy (range 0-20). Similarly, cut-off points of 150 were used to group participants into high $(\geq 150)$ or low $(<150)^{41}$ level diabetes self-management self-efficacy (maximum score 200). Also, patients were grouped into normal or below $\mathrm{HbA} 1 \mathrm{c}<6 \%$. Quantitative data were reclassified into categories or groupings.

The first five interviews, including five face-to-face interviews and five telephone-based follow-up interviews, were transcribed in full in Chinese and translated into English for all research team members. The remaining interviews were transcribed and coded in Chinese and were reviewed and validated by a second bilingual researcher (Chinese and English). Regular meetings with all researchers enabled questioning of any potential assumptions.

Interview data were analysed using thematic analysis. ${ }^{42}{ }^{4}$ Initially, an open coding process was used, with codes entered into NVivo 11 (QSR International, 2017). ${ }^{44}$ Then, use of NVivo software enabled integration of qualitative and quantitative data ${ }^{45}$ by systematically matching interview data to demographic or clinical outcomes data (eg, gender, body mass index and HbA1c) and information from survey responses. Quantitative scores for scales were given qualitative categories (sufficient or limited education) (qualitative text codes) for the purposes of segmenting interview data based on groupings. Meta-inferences were brought together through matrix approaches within computer software NVivo $11,{ }^{3444}$ and then through exploration using the query function. For example, we compared participants with high C-DMSES scores with their interview transcripts describing how they managed their diet, exercise or blood glucose monitoring to those with low C-DMSES scores. Finally, narrative reporting of the new themes captured during this process represented the meta-inferences (see figure 1).

\section{Data integration}

At the study design level, qualitative data were linked with quantitative data, in terms of the timing of data collection and the complementary nature of the data being collected. The quantitative data were used to analyse how health education influences patients' knowledge, their self-efficacy abilities and key ACS and T2DM outcome measures and complemented the qualitative data collected through 
patient interviews, to better inform the social context influencing behavioural change. At the methods level, a merging approach was used to bring the two databases together for analysis and comparison. ${ }^{46}$ Qualitative data were collected drawing on parallel questions included in the three standardised scales, which means quantitative data were collected using a series of scales and qualitative data were collected from patients using an interview schedule that is made up of parallel and similar questions. ${ }^{31}$ For example, items (nutrition, physical exercise and weight, medical treatment and blood sugar check) about the self-management changes from the C-DMSES were included in the follow-up interview schedule. At the level of interpretation and reporting, two kinds of data were compared, participants' scores on the scales with text data from their interview transcripts. ${ }^{43}$ Finally, a narrative approach was used to report integrated quantitative and qualitative results on a theme-by-theme basis, ${ }^{31}$ (see figure 1).

\section{Rigour}

During the interview, notes on important points were taken. Interviewing techniques, questions and the coding tree were checked by all four researchers. Interviews were conducted until data saturation was achieved when no new themes or ideas were identified. ${ }^{47}$ To ensure consistency survey and interview data were collected by a single researcher. The healthcare record review tool was piloted by two authors and demonstrated high inter-rater reliability. ${ }^{33}$ Regular meetings with all team members enabled questioning of any potential assumptions.

\section{Patient and public involvement}

The final published paper will be provided to all participants by email (where participants have requested). Patients and/or the public were not involved in the study design. ${ }^{48}$

\section{RESULTS}

\section{Participant characteristics}

Most patients with ACS and T2DM (166/160, 96.4\%) were willing to participant in the survey; however, six patients that met the selection criteria declined to participate (four females, two males). Of the 160 survey participants, 68 participants were asked if they were interested in being interviewed, of whom most were male $(n=47,69 \%)$. However, less than a third consented to be interviewed $(\mathrm{n}=21,31 \%)$ of which a large majority was male $(\mathrm{n}=18$, $86 \%$ ). Quantitative data were used from a subset of 18 males and 3 females who completed the initial survey and participated in the interviews. Participants ranged in age from 35 to 79 years and had been diagnosed with T2DM for between 0.5 and 20 years (see table 1 ).

\section{Connecting perceived health education, knowledge to perceived self-management self-efficacy}

In order to understand the experiences and perspectives of participants with high and low self-efficacy or sufficient and limited health education, the participants were
Table 1 Characteristics of participants

\begin{tabular}{crl}
\hline & $\mathbf{N}(\%)$ & Mean \pm SD \\
\hline Gender & & \\
Female & $3(14.3)$ & - \\
Male & $18(85.3)$ &
\end{tabular}

\section{Age (years)}

$\begin{array}{lcl}35-44 & 3(14.3) & \\ 45-54 & 2(9.5) & \\ 55-64 & 8(38.1) & 60.6 \pm 11.6 \\ 65-74 & 6(28.6) & \\ 75-84 & 2(9.5) \\ \text { Diagnosis } & \\ \text { NSTEMI } & 12(57.1) \\ \text { STEM } & 7(33.3) \\ \text { Unstable angina } & 2(9.5) \\ \text { Hypertension } & 17(81.0) \\ \text { Hyperlipoidaemia } & 3(14.3) \\ \text { Atrial fibrillation } & 2(9.5) \\ \text { Artificial knee joint } & 1(4.8) \\ \text { Hepatic adipose } & 1(4.8) \\ \text { infiltration } & \end{array}$

\begin{tabular}{|c|c|c|}
\hline \multicolumn{3}{|c|}{ Diagnosed with T2DM (years) } \\
\hline $0-5$ & $10(47.6)$ & \\
\hline $6-10$ & $5(23.8)$ & $7.7 \pm 6.0$ \\
\hline $11-15$ & $4(19.0)$ & \\
\hline $16-20$ & $2(9.5)$ & \\
\hline BMI $\left(\mathrm{kg} / \mathrm{m}^{2}\right)$ & - & $\begin{array}{l}\text { Median, 25.1; IQR, } 23.7 \\
\text { to } 29.9 \text { (BMI from one } \\
\text { participant missing) }\end{array}$ \\
\hline $\mathrm{HbA1c}(\%)$ & - & $\begin{array}{l}7.8 \pm 1.7 \text { ( } \mathrm{HbA} 1 \mathrm{c} \text { one } \\
\text { participant's data missing) }\end{array}$ \\
\hline LDL (mmol/L) & - & $\begin{array}{l}2.3 \pm 0.9 \text { (LDL two } \\
\text { participants' data missing) }\end{array}$ \\
\hline \multicolumn{3}{|l|}{ C-DKS (total 8) } \\
\hline$<4$ & 0 & median, 7 ; IQR, 6 to 7 \\
\hline$\geq 4$ & $21(100.0)$ & \\
\hline \multicolumn{3}{|c|}{ C-DMSES (total 200) } \\
\hline$<150$ & $13(61.9)$ & $137.2 \pm 34.1$ \\
\hline$\geq 150$ & $8(38.1)$ & \\
\hline VAS scores (BL) & - & $58.3 \pm 24.8$ \\
\hline VAS scores (HD) & - & $47.1 \pm 27.2$ \\
\hline
\end{tabular}

Data reported here were obtained from the survey and patient healthcare record review reported in detail elsewhere. ${ }^{33}$ $\mathrm{BL}$, education relating to blood sugar problems; BMI, body mass index; C-ACSRI, Chinese version of Acute Coronary Syndrome Response Index; C-DKS, Chinese version of Diabetes Knowledge Scale; C-DMSES, Chinese version of Diabetes Management Self efficacy Scale; HbA1c, glycosylated haemoglobin; HD, education relating to heart disease; $\mathrm{HD}$, education relating to heart disease; LDL, low-density lipoprotein; NSTEMI, non-ST-elevation myocardial infarction; STEMI, ST-elevation myocardial infarction; T2DM, type 2 diabetes mellitus cholesterol; VAS, visual analogue scale.

divided into eight groups (see table 2): only four participants (A, B, E, J) (in Group 1 and Group 5) reported both receiving sufficient education (VAS score $>50$ ) and 
Table 2 Grouping of the participants (A-U)

\begin{tabular}{|c|c|c|c|c|c|}
\hline & \multicolumn{2}{|l|}{ ACS related self-efficacy } & & \multicolumn{2}{|l|}{ Diabetes related self-efficacy } \\
\hline & Scores & Patient & & Scores & Patient \\
\hline Group 1 & $\begin{array}{l}\text { High self-efficacy (C-ACSRI } \\
\text { score } \geq 15 \text { ) with sufficient } \\
\text { cardiac education (VAS score } \\
>50 \text { ) }\end{array}$ & $A, B, E, J$ & Group 5 & $\begin{array}{l}\text { High self-efficacy (C-DMSES } \\
\text { score } \geq 150 \text { ) with sufficient } \\
\text { diabetes education (VAS score } \\
>50 \text { ) }\end{array}$ & $\begin{array}{l}\mathrm{A}, \mathrm{B}, \mathrm{E}, \mathrm{F}, \mathrm{G}, \mathrm{J}, \mathrm{K} \\
\mathrm{O}, \mathrm{Q}\end{array}$ \\
\hline Group 2 & $\begin{array}{l}\text { High self-efficacy (C-ACSRI } \\
\text { score } \geq 15 \text { ) with limited cardiac } \\
\text { education (VAS score } \leq 50 \text { ) }\end{array}$ & $\mathrm{O}$ & Group 6 & $\begin{array}{l}\text { High self-efficacy (C-DMSES } \\
\text { score } \geq 150 \text { ) with limited } \\
\text { diabetes education (VAS score } \\
\leq 50 \text { ) }\end{array}$ & \\
\hline Group 3 & $\begin{array}{l}\text { Low self-efficacy (C-ACSRI } \\
\text { score }<15 \text { ) with sufficient } \\
\text { cardiac education (VAS score } \\
>50 \text { ) }\end{array}$ & $\mathrm{F}, \mathrm{I}, \mathrm{L}, \mathrm{Q}, \mathrm{R}$ & Group 7 & $\begin{array}{l}\text { Low self-efficacy (C-DMSES } \\
\text { score }<150 \text { ) with sufficient } \\
\text { diabetes education (VAS score } \\
>50 \text { ) }\end{array}$ & I, L, M, R, S, T \\
\hline Group 4 & $\begin{array}{l}\text { Low self-efficacy (C-ACSRI } \\
\text { score }<15 \text { ) with limited } \\
\text { cardiac education (VAS score } \\
\leq 50)\end{array}$ & $\begin{array}{l}\text { C, D, G, H, K, M, } \\
\text { N, P, S, T, U }\end{array}$ & Group 8 & $\begin{array}{l}\text { Low self-efficacy (C-DMSES } \\
\text { score }<150 \text { ) with limited } \\
\text { diabetes education (VAS score } \\
\leq 50 \text { ) }\end{array}$ & $\mathrm{C}, \mathrm{D}, \mathrm{H}, \mathrm{N}, \mathrm{P}, \mathrm{U}$ \\
\hline
\end{tabular}

All interview data were segmented into these combinations to further examine the textual data using the matrix and query function of Nvivo. ACS, acute coronary syndrome; C-ACSRI, Chinese version of Acute Coronary Syndrome Response Index; C-DMSES, Chinese version of Diabetes Management Self efficacy Scale; VAS, visual analogue scale.

believed they had high self-management self-efficacy in both ACS and diabetes. Most of the participants $(n=17)$, did not perceive they had sufficient education or abilities to manage both conditions. More concerning was that most participants (Groups 3-4) (16/21), reported low self-efficacy in managing ACS symptoms, while reporting they received limited or sufficient education. This study used matrix approaches within NVivo 11 to segment the qualitative data based on specific groups of participants' (educational level by self-efficacy) and their interview responses or textual data, demonstrating expansion and divergence.

Analysis of the quantitative data provided some understanding of the education and knowledge received by participants and how this was related to their perceived ability to manage either their ACS symptoms or their diabetes. These data were then integrated within the major themes identified through the qualitative analysis (included in the indicative quotes provided). The narrative integration of the quantitative and qualitative data also provided an important context to explore the behavioural changes from the inpatient setting into the community.

\section{Thematic analysis with data integration}

Three major themes and seven subthemes were identified (see table 3).

\section{Theme 1: self-management of ACS and T2DM represents a} complex interplay between individual self-efficacy, knowledge and skills

A key finding was that participants' self-management was a dynamic and complex process, including an interplay of factors relating to threat and health priorities. Within this theme, two subthemes were identified.

Subtheme 1: optimal self-management is difficult to attain and maintain requiring knowledge of disease and health threat and prioritising of treatment and healthy behaviours, often with no symptoms

Participants emphasised the difficulties in achieving metabolic control, exercise and adopting a healthy lifestyle, in their follow-up interviews.

\section{Managing a condition with concealed symptoms and/or feeling well}

Participants with low self-efficacy were more likely to report that they neglected their condition, particularly for diabetes. As the most common symptom of diabetes is " $n o$ symptoms', feeling well could be viewed as a point whereby good behaviours were lost or becoming 'off guard', which could also be seen in the confidence displayed from 'being stable' which was a time for not 'strictly' adhering to advice, as Participant I with low self-efficacy, notes:

'But sometimes these problems are ignored when I feel better, it is easier to ignore when my health conditions were relatively stable, easier to be off guard. I don't think it's necessary to strictly follow the physician's advice when my health conditions were relatively stable.' (Patient I, interview in hospital)

Whether feeling good or being stable, these situations were seen as an opportunity to deviate from recommended treatment or behaviour, with the potential to return the participant to feeling unwell and becoming unstable. 
Table 3 Themes and subthemes

\begin{tabular}{|c|c|c|}
\hline Themes & Subthemes & \\
\hline $\begin{array}{l}\text { Self-management of ACS and T2DM } \\
\text { represents a complex interplay between } \\
\text { individual self-efficacy, knowledge and } \\
\text { skills }\end{array}$ & $\begin{array}{l}\text { Optimal self-management is difficult to attain and } \\
\text { maintain requiring knowledge of disease and health } \\
\text { threat and prioritising of treatment and healthy } \\
\text { behaviours, often with no symptoms }\end{array}$ & $\begin{array}{l}\text { (1) Managing a condition with concealed } \\
\text { symptoms and/or feeling well } \\
\text { (2) Identifying cardiac symptoms and } \\
\text { seeking medical attention } \\
\text { (3) Blood glucose self-monitoring } \\
\text { (4) Diet regulation } \\
\text { (5) Regular physical exercise }\end{array}$ \\
\hline \multirow[t]{2}{*}{$\begin{array}{l}\text { Social environment is integral to lifestyle } \\
\text { and behaviour change }\end{array}$} & $\begin{array}{l}\text { Healthy and unhealthy behaviours were formed and } \\
\text { sustained through social interaction and support within } \\
\text { the local community }\end{array}$ & \\
\hline & Family as a support and decision-making system & \\
\hline \multirow[t]{2}{*}{$\begin{array}{l}\text { Managing multiple health conditions } \\
\text { requires body and mind systems } \\
\text { harmony }\end{array}$} & $\begin{array}{l}\text { 'Three Brothers': familial inheritance and close } \\
\text { interrelations exist between ACS, T2DM and } \\
\text { hypertension }\end{array}$ & \\
\hline & $\begin{array}{l}\text { Balancing the use of both eastern and western } \\
\text { medicine to manage multiple conditions. }\end{array}$ & \\
\hline
\end{tabular}

ACS, acute coronary syndrome; T2DM, type 2 diabetes mellitus.

\section{Identifying cardiac symptoms and seeking medical attention} For ACS, participants with high C-ACSRI scores, who perceived they received more cardiac health education, were more likely to initiate their own help-seeking behaviours when needed. But participants with low C-ACSRI scores indicated a lack of awareness of symptom recognition and treatment for an ACS event. For example, Patient $\mathrm{N}$ who perceived he received limited health education and had low self-efficacy in ACS symptom management, said:

'I never thought I would have heart disease, even when I had severe chest pain. I thought it was just muscular spasm or nerve pain.' (Patient N, interview in hospital)

\section{Blood glucose self-monitoring}

Six participants who perceived they received sufficient health education or had high self-efficacy described having lower or 'normal blood glucose' during the interviews. However, participants generally reported that they did not check their blood glucose level regularly at home, even those participants who bought a glucometer machine. Those participants without a glucometer at home reported that they only checked their blood glucose when they visited the hospital. Patient $\mathrm{O}$ with a high C-DMSES score stated that he checked his blood glucose once per half year due to health insurance coverage, thus necessitating that he manages his health conditions by his 'feelings'?

'Basically did not [check the blood sugar level]. I rarely came to the hospital because we don't have health insurance cover for going to see doctors in the outpatient clinic here. I would go for regular check-ups about every half a year when I go back to Yangzhou. I now monitor my health by my own feelings.' (Patient $\mathrm{O}$, interview at home)

Most participants did not monitor their blood glucose level unless they were unstable. Ongoing blood glucose self-monitoring is often recommended for individuals with diabetes who are using insulin and the method and frequency of self-monitoring should reflect their individual circumstances and aims of treatment. ${ }^{49}$

\section{Diet regulation}

Participants reported several strategies to manage diet although they also identified that this was difficult to achieve. Reducing the food amount especially carbohydrates and sugar as well as reducing salt intake ('light diet') and meat ('more vegetables instead of meat') were commonly reported. Even so, some participants with low C-DMSES scores were less likely to adopt a healthy diet at home. For example, Patient $\mathrm{L}$ described knowing that he needed to reduce his salt intake but he did not adhere to this:

'They know my taste is heavy [I like salt]. When ... the food [is] on [the] dining table, I said I was not hungry. Then I would add some salt into the dishes when they finished eating.' (Patient L, interview in hospital)

\section{Regular physical exercise}

Despite the benefits of physical exercise, 11 participants who perceived they received limited health education or had a low C-DMSES score, did not undertake regular exercise describing lack of motivation, poor health conditions 
and unwillingness or fear of exercise. However, after experiencing an ACS event, participants were more likely to exercise and most participants described that they would increase their intensity of exercise gradually at home. As one participant with limited health education and low C-DMSES score, notes:

'It is impossible for me to run for two hours daily. I will increase my exercise level gradually.' (Patient N, interview at home)

\section{Subtheme 2: a critical cardiac event motivates a strong desire to} live longer and well and manage their diabetes

ACS is an acute life-threatening condition and most participants were more motivated to change their lifestyle and improve their self-management of diabetes after experiencing an ACS event. The desire to live longer is illustrated in the following quote:

'In order to live longer and live well...saving [my] life is the most important thing for me' (Patient P, interview in hospital)

ACS was described by most participants as a 'serious consequence' of having diabetes. Participants presented that they should pay more attention to diabetes as they were 'already sick' or found diabetes could lead to serious cardiac problems. For example, Patient $\mathrm{N}$ who perceived he received limited health education and had low self-efficacy, described that:

'I didn't feel any symptoms...so I didn't control it [diabetes] at all. However, I should pay more attention since I am already sick [have ACS]. Now I am serious when looking at the health problems and the life habits [I] need to pay more attention.' (Patient N, interview in hospital)

\section{Theme 2: social environment is integral to lifestyle and behaviour change}

Participants described ACS and diabetes-related healthy and unhealthy behaviours and lifestyle changes were always intricately linked to their social environment. Within this theme, two subthemes were identified.

Subtheme 1: healthy and unhealthy behaviours were formed and sustained through social interaction and support within the local community

While participants understood the need to change their lifestyle, they identified the impact of social factors on attempts to adopt health promoting behaviours. For example, Patient $J$ who received sufficient health education and had high self-efficacy, described the work culture where social occasions that promoted poor diet, related to his occupation, were frequent:

'I was the purchasing department manager, purchasing department had a lot of social events, the customer if you did not have a meal with the customer, he would worry about his business, (you) have to go to these business dinners... Eating very greasy food; I do not eat at the restaurant now, oil, [artificial] colours too much.' (Patient J, interview in hospital)

Some health promoting behaviours, such as exercise were part of socialising within their local community. One example discussed by participants is square dancing, which is very popular in China, particularly for elderly people. For example, Patient $\mathrm{O}$ who perceived he received sufficient diabetes education described he had adopted square dancing with an appropriate intensity as their daily exercise training:

'I usually do some dancing with music with other older persons for about one to one and a half hours in .[the]...park in the morning. It is around eight ...to nine o'clock or nine thirty after breakfast. At around a quarter past seven after dinner, I have 2 hours dancing on the square.' (Patient O, interview in hospital)

Participants also discussed the difficulty of smoking cessation and related this to social norms, particularly for participants with low self-efficacy. Patient L with low self-efficacy discussed the different environments of the hospital and home and how this could result in a return to smoking after discharge:

'I haven't smoked for a week since being in the hospital. But being at home is different. It is mainly due to the environment, which is very important. If everyone around me doesn't smoke, I can stop smoking. However, it is difficult to quit smoking when everyone else still smokes.' (Patient L, interview in hospital)

\section{Subtheme 2: family as a support and decision-making system}

Chinese culture has strong familial ties with family members and this was evident among all participants. Family 'supervision' was perceived as very important for helping individuals change unhealthy habits even for participants with high perceived diabetes management self-efficacy, for example, Patient $Q$ described that:

'I need family supervision, especially men, my wife supervises me, first to change the bad habit of smoking, I have not drank wine for a long time.... some parties, playing cards, these cannot be changed but now, completely [do] not attend. Family supervision is very important; develop good habits, maintain good habits, and change bad habits'. (Patient $\mathrm{Q}$ interview in hospital)

Family members were involved in the decision-making about seeking medical treatment, particularly for patients with perceived limited health education or with low perceived self-efficacy. For example, Patient $\mathrm{S}$ described that:

'My children always told me go to the hospital, I do not want to go to the hospital because I do not know which department that I need to visit, I have this disease [diabetes] and also have that [heart disease]. I 
do not like to go to the hospital, I just like to endure it and it's okay for me.' (Patient S, interview in hospital)

\section{Theme 3: managing multiple health conditions requires body} and mind systems harmony

Participants described that maintaining harmony was an important concept to understanding and managing their multiple health conditions. Harmony is a cultural value for Chinese society and it is one of the key elements of Traditional Chinese medicine (TCM) that leads to good health. ${ }^{50}$ Within this theme, three subthemes were identified.

\section{Subtheme 1: 'Three Brothers': familial inheritance and close} interrelations exist between ACS, T2DM and hypertension

Participants who perceived they received sufficient health education were more likely to have a sophisticated understanding of their health conditions. For example, Patient $\mathrm{J}$ who perceived he had received sufficient health education refers to his conditions-ACS, T2DM and hypertension - as the 'three brothers' to describe the link between the conditions as well as the connection to the inheritance of genetic predisposition to the conditions. The three brothers analogy also implies that the conditions are closely connected to each other and share common features (similar risk factors).

'My... trouble is inherited from my father, family disease, diabetes, hypertension, and another one is coronary heart disease. People call them 'three brothers', I have them all.' (Patient J, interview in hospital)

Many participants described that ACS and hypertension were the complications of T2DM, and the consequences of atherosclerosis or arteriosclerosis within blood vessels were considered just like 'corrupting the mechanical piping system' as described by Patient $Q$ who perceived he received sufficient health education.

'Pipeline corrosion is a strong corrosion, the corrosion [of blood sugar] slowly leads to vascular corrosion, then the blood vessels are not very smooth, along with high fat in blood vessels are more and more narrow, therefore the blood flow is small, but the pressure is big, and the blood supply to the heart is insufficient'. (Patient $Q$, interview in hospital)

\section{Subtheme 2: 'Human body like a factory (system)': Health was} achieved by forming an harmonious state

One important Chinese health belief is the holism principle which emphasises harmony within the universe, such as disturbing the balance or harmony within nature will result in illness according TCM and Taoism. ${ }^{46}$ Restoring 'Harmony within the human body system' is an important approach to resolving the health concerns. As Patient $\mathrm{Q}$ described that:

'Our endocrine system and circulatory system, the human body consist of several systems, such as cardiac, brain and vascular system, nervous system, like a factory there are a lot of systems, mechanical system, computer system...functions of one system and cooperate with other systems and then no problems, this can be an harmonious whole.' (Patient $\mathrm{Q}$, interview in hospital)

Subtheme 3: balancing the use of both eastern and Western medicine (WM) to manage multiple conditions

TCM typically uses non-invasive and natural therapies such as herbal medicine, but western medicine (WM) is perceived as using more invasive or chemically based treatments such as surgery or pharmaceuticals. ${ }^{51}$ Participants emphasised that treatment of ACS and T2DM was based on WM, but they also did describe preferring TCM products in the early stages of an illness. For example, Patient J described that:

'My two friends asked me to choose conservative treatment, I said it was best [to] not put the heart stent [in]. Heart stents in foreign countries have been less popular, they say your condition is not very severe, should use conservative treatment.' (Patient J, interview in hospital)

Moreover, the complications of diabetes, such as peripheral vascular disease, prompted patients to engage in various health practices. But participants who perceived they received limited health education or with low perceived self-efficacy, were more passive when using both TCM and WM. Patient U describes when WM failed then tried TCM (or vice-versa):

'[Diabetic foot] I went to see western medicine first and [they] did not cure [the foot], then [I went to receive] traditional Chinese medicine.' (Patient U, interview in hospital).

\section{DISCUSSION}

This study aimed to explore how the health education received by patients with comorbid ACS and T2DM, influenced their self-efficacy, self-management and behaviour changes on discharge and follow-up at home. Most of the participants in this study were male. The prevalence of ACS is lower for females than males and the percentage of females diagnosed is reported as $23 \% .^{52}$ Moreover, female patients with ACS have a poorer prognosis including higher mortality than men ${ }^{53}$ as well as tending to be older at presentation. ${ }^{54}$

Health education and perceived self-efficacy remain essentialfactorsin supportingself-managementbehaviours among people with ACS and T2DM. Both self-management and changes in behaviour among patients with ACS and T2DM were influenced by the individuals' priorities, social roles and norms and cultural values. In addition, maintaining harmony was an important concept to understanding and managing multiple health conditions among Chinese patients with ACS and T2DM. The findings of this study are similar to those of another qualitative 
study that conducted focus group interviews with patients with T2DM following a recent ACS event. ${ }^{2}$ Patients with both ACS and T2DM reported difficulty integrating lifestyle changes and treatment regimes and needed tailored support after discharge from the hospital. ${ }^{2}$ Support available to this sample was mostly related to family support rather than other local health services.

Providing ongoing education and regular follow-up with patients and their family are essential, ${ }^{2}{ }^{25}$ including ongoing measurement of patients' self-efficacy and their achievement of goals. ${ }^{25}$ Within this sample of study participants with both ACS and T2DM, only four participants perceived they received sufficient education and believed they had high self-efficacy to manage their conditions, even though all participants had adequate diabetes knowledge. Further to this just over half of the participants with either sufficient or limited diabetes education reported low diabetes self-management self-efficacy or potentially that they may not be able to manage their diabetes. Similarly, a very high proportion (16 of 21) of participants reported low self-efficacy in relation to managing ACS symptoms with either limited or sufficient cardiac education.

In this study, although many participants had had diabetes for a significant number of years (mean 8 years), the damage to blood vessels caused from poor lifestyle or diabetes management, was made acutely aware to participants when they experienced their ACS event. When participants either had no symptoms or when they felt well, they stopped doing the required behaviours, or they perceived the threat was diminished.$^{55}$ In one way, experiencing the ACS event, may be creating for the first time, the level of threat (or perceived severity of condition) that should have been understood when the individual was first diagnosed with T2DM. ${ }^{56}$ Educational interventions should consider how these approaches could be adapted to deliver educational messages that unmask the real threat to health of diabetes and related poor lifestyle factors.

Participants reported that social interaction influenced them, including positive as well as negative effects. Specifically, social activities, such as square dancing were reported as beneficial for participants. Dancing is an appropriate exercise promoting regular physical activity and improving patients' clinical outcomes among patients with diabetes. $^{57-59}$

Social influences were also a barrier for participants to change their unhealthy behaviours, such as smoking. The high prevalence of smoking in China within the community makes it difficult to quit as described by many participants. Chinese smokers are aware of the benefits of quitting smoking to protect their children's health and health education could emphasise this potential. ${ }^{60}$ Moreover, community-based or national antismoking campaigns are urgently needed. ${ }^{61}$

ACS, T2DM and hypertension, referred to as the 'Three Brothers' provides a platform for focusing treatment and self-management to include hypertension as an important third, related, somewhat less emphasised, condition. These three conditions highlight the inheritance of genetic predisposition and the close connection to each other in terms of risk factors and required lifestyle change.$^{62}$ Familial risk factors among these three health conditions further support the need for a family-oriented approach to health education. Family-oriented educational interventions consider the context in which the health condition occurs, including the familial risk factors, ${ }^{63}$ and are recommended.

Traditionally, Chinese people emphasise harmony within the universe and disturbing the balance or harmony within nature will result in illness. ${ }^{50}$ The aim of medicine is to restore the balance of Yin and Yang within the body. ${ }^{64}$ To achieve these, individuals have to follow a healthy lifestyle, spiritual toning and other approaches to keep all the elements in life in balance. ${ }^{64}$ For Chinese patients, health professionals should consider the use of maintaining mind and body harmony and analogies of systems (whole body) to promote engagement by participants.

The study was conducted at one major hospital in Shanghai and represents a small number of participants who are mainly male. The findings may therefore be applicable to other similar samples or contexts or conditions, but do not represent findings that are generalisable to the population. Significantly more females declined to participate in the interviews. Total 68 participants (21 females and 47 males) were asked if they were interested in being interviewed at two later time points. Only 3 of the 21 females (14.3\%) consented to be interviewed. As female patients with ACS have a poorer prognosis and tend to be older at presentation than men, ${ }^{54}$ our findings primarily reflect the perceptions of men. Further research that investigates the perceptions of women with T2DM and ACS is recommended. The follow-up interview time of participants was up to 4 weeks, while several studies have demonstrated that changes in behaviour may occur from 2 to 8 months. ${ }^{65}$ Studies conducted at regular intervals over a 12-month period are recommended.

\section{Validity (Legitimation)}

Although there are numerous aspects of validity (legitimation $)^{66} 67$ to be considered in mixed methods studies, we highlight five specific aspects of importance to this specific study. Meta-inferences were brought together through matrix approaches within computer software NVivo $11^{3444}$ to segment the data based on groupings and then through exploration using the query function, specific groups of participants' (educational level by self-efficacy) interview responses or textual data could be examined, demonstrating expansion and some divergence $^{31}$ in the two sets of data. Narrative reporting of the new themes captured during this process represents the meta-inferences. Commensurability approximation (use of both worldviews of quantitative and qualitative) was supported by the diversity of the authors and team. Our team consisted of bilingual researchers (2), qualitative researchers (3) and quantitative researchers (3), with 
researchers having multiple roles. Sample integration was supported with a single sample where both quantitative and qualitative data were directly integrated for analysis and reporting. ${ }^{66}$ Pragmatic legitimation was verified by the pattern of behaviour changes and the influences on these changes that were demonstrated within the findings. ${ }^{66} 67$ Finally, integration has occurred at design, analysis and reporting phases of this study.

Expansion of information was evident in the qualitative data versus quantitative data, with complex understandings of the relationship between ACS, diabetes and hypertension being described by participants within a familial context. Divergence of the data sets was found in relation to specific behaviours that were described within the quantitative data and then the qualitative data, where behaviour is embedded within the context of the social environment. For example, although participants were not smoking in the hospital, this changed when interacting within a community where smoking is a social norm. Overall there was confirmation, within the quantitative and qualitative data, of the lack of perceived ability to manage both conditions within the home environment, particularly relating to ACS and the ongoing difficulties that lifestyle changes required of the participants.

\section{CONCLUSION}

The limited inpatient education experienced by these participants was not found to be supportive of the participants' confidence to manage either their diabetes or ACS on discharge. In particular, very low self-efficacy was evident in relation to managing symptoms and seeking help relating to ACS, and this should be a major focus of any education programme. Healthy lifestyle changes such as square dancing provided a positive socially enhanced behaviour. Health education programmes, that deliver culturally-appropriate content for Chinese people (particularly men) experiencing both diabetes and ACS, should consider the use of the need to restore and maintain mind and body harmony after an ACS event, include family members and the 'Three Brothers' (ACS, T2DM, hypertension).

Community-based public health programmes, which deliver appropriate messages on the seriousness of the hidden effects of smoking and high sugar diets or diabetes on cardiovascular health, are urgently needed. Further research, testing these constructs within an educational intervention is recommended.

\footnotetext{
Author affiliations

${ }^{1}$ Shenzhen Nanshan People's Hospital, Shenzhen, China

${ }^{2}$ School of Nursing, Midwifery \& Paramedicine, Australian Catholic University (McAuley Campus), Brisbane, Queensland, Australia

${ }^{3}$ Tenth People's Hospital of Tongji University, Shanghai, China

${ }^{4}$ School of Nursing, Jinggangshan University, Ji'an, China

${ }^{5}$ School of Allied Health, Human Services and Sport, La Trobe University, Melbourne, Victoria, Australia

${ }^{6}$ Allied Health, Royal Melbourne Hospital, Melbourne, Victoria, Australia

${ }^{7}$ School of Nursing, Midwifery and Paramedicine, University of the Sunshine Coast (USC), Sippy Downs, Queensland, Australia
}

${ }^{8}$ Honorary Research Fellow, Royal Brisbane and Women's Hospital (RBWH), Herston, Queensland, Australia

${ }^{9}$ Honorary Research Fellow, Mater Medical Research Institute-University of Queensland (MMRI-UQ), Brisbane, Queensland, Australia

${ }^{10}$ Nursing Research \& Practice Development Centre, The Prince Charles Hospital Metro North Health Service District, Brisbane, Queensland, Australia

${ }^{11}$ Faculty of Health Sciences, University of the Witwatersrand, Johannesburg, South Africa

${ }^{12}$ Faculty of Health Sciences, Australian Catholic University, Sydney, New South Wales, Australia

${ }^{13}$ Ingham Institute for Applied Medical Research, Liverpool, New South Wales, Australia

Acknowledgements The authors would like to thank the participants of this study as well as the staff at the research site for their support and collaboration.

Contributors Study conception and design: XL-L, MJ, KW, C-JW, YS, PF. Data collection: XL-L, YS. Data analysis: XL-L, MJ, KW, C-JW, PF, YS. Manuscript drafts and revisions: XL-L, MJ, KW, C-JW, PF, YS. ICMJE criteria for authorship read and met: XL-L, KW, C-JW, YS, PF, MJ. Agreed with manuscript results and conclusions $\mathrm{XL}-\mathrm{L}, \mathrm{KW}, \mathrm{C}-\mathrm{JW}, \mathrm{YS}, \mathrm{PF}, \mathrm{MJ}$. All authors approved the final manuscript and act as guarantors for the study.

Funding There are no funders to report for this submission. The first author received a PhD stipend from Australian Catholic University.

Competing interests None declared.

Patient consent for publication Not required.

Provenance and peer review Not commissioned; externally peer reviewed.

Data availability statement All data relevant to the study are included in the article or uploaded as supplementary information.

Open access This is an open access article distributed in accordance with the Creative Commons Attribution Non Commercial (CC BY-NC 4.0) license, which permits others to distribute, remix, adapt, build upon this work non-commercially, and license their derivative works on different terms, provided the original work is properly cited, appropriate credit is given, any changes made indicated, and the use is non-commercial. See: http://creativecommons.org/licenses/by-nc/4.0/.

\section{REFERENCES}

1. Hung WW, Ross JS, Boockvar KS, et al. Recent trends in chronic disease, impairment and disability among older adults in the United States. BMC Geriatr 2011;11:47.

2. Kasteleyn MJ, Gorter KJ, van Puffelen AL, et al. What follow-up care and self-management support do patients with type 2 diabetes want after their first acute coronary event? A qualitative study. Prim Care Diabetes 2014;8:195-206.

3. Tanash Mu'ath Ibrahim, Fitzsimons D, Coates V, et al. An evaluation of the effectiveness of self-management interventions for people with type 2 diabetes after an acute coronary syndrome: a systematic review. J Clin Nurs 2017;26:1458-72.

4. Burke LA, Rosenfeld AG, Daya MR, et al. Impact of comorbidities by age on symptom presentation for suspected acute coronary syndromes in the emergency department. Eur J Cardiovasc Nurs 2017;16:511-21.

5. Saleh A, Hammoudeh AJ, Hamam I, et al. Prevalence and impact on prognosis of glucometabolic states in acute coronaRY syndrome in a middle Eastern country: the GLucometabolic abnOrmalities in patients with acute coronaRY syndrome in Jordan (glory) study. Int $J$ Diabetes Dev Ctries 2012;32:37-43.

6. Paneni F, Beckman JA, Creager MA, et al. Diabetes and vascular disease: pathophysiology, clinical consequences, and medical therapy: Part I. Eur Heart J 2013;34:2436-43.

7. Donahoe SM, Stewart GC, McCabe CH, et al. Diabetes and mortality following acute coronary syndromes. JAMA 2007;298:765-75.

8. Gholap NN, Achana FA, Davies MJ, et al. Long-Term mortality after acute myocardial infarction among individuals with and without diabetes: a systematic review and meta-analysis of studies in the post-reperfusion era. Diabetes Obes Metab 2017;19:364-74.

9. Lakerveld J, Bot SDM, Chinapaw MJ, et al. Primary prevention of diabetes mellitus type 2 and cardiovascular diseases using a cognitive behavior program aimed at lifestyle changes in people at risk: design of a randomized controlled trial. BMC Endocr Disord 2008;8:6 
10. Wu C-JJ, Chang AM, McDowell J. Innovative self-management programme for diabetics following coronary care unit admission. Int Nurs Rev 2009;56:396-9.

11. CJJ W, Atherton JJ, Maclsaac RJ, et al. Effectiveness of the cardiacdiabetes transcare program: protocol for a randomised controlled trial. BMC Health Serv Res 2017;17.

12. Jang $\mathrm{Y}, \mathrm{Yoo} \mathrm{H}$. Self-Management programs based on the social cognitive theory for Koreans with chronic disease: a systematic review. Contemp Nurse 2012;40:147-59.

13. Mohebi S, Azadbakht L, Feizi A, et al. Review the key role of selfefficacy in diabetes care. J Educ Health Promot 2013;2.

14. Fraser SN, Rodgers WM. The influence of general and exercise specific social support on Self-Efficacy for overcoming barriers to cardiac rehabilitation ${ }^{1}$. J App/ Soc Psychol 2012;42:1811-29.

15. Ha M, Hu J, Petrini MA, et al. The effects of an educational selfefficacy intervention on osteoporosis prevention and diabetes selfmanagement among adults with type 2 diabetes mellitus. Biol Res Nurs 2014;16:357-67.

16. Al-Khawaldeh OA, Al-Hassan MA, Froelicher ES. Self-Efficacy, selfmanagement, and glycemic control in adults with type 2 diabetes mellitus. J Diabetes Complications 2012;26:10-16.

17. Lin K, Park C, Li M, et al. Effects of depression, diabetes distress, diabetes self-efficacy, and diabetes self-management on glycemic control among Chinese population with type 2 diabetes mellitus. Diabetes Res Clin Pract 2017:131:179-86.

18. Fort MP, Alvarado-Molina N, Peña L, et al. Barriers and facilitating factors for disease self-management: a qualitative analysis of perceptions of patients receiving care for type 2 diabetes and/or hypertension in San José, Costa Rica and Tuxtla Gutiérrez, Mexico. BMC Fam Pract 2013;14.

19. Jo Wu C-J, Chang AM, McDowell J. Perspectives of patients with type 2 diabetes following a critical cardiac event - an interpretative approach. J Clin Nurs 2008;17:16-24.

20. Been-Dahmen JMJ, Dwarswaard J, Hazes JMW, et al. Nurses' views on patient self-management: a qualitative study. $J$ Adv Nurs 2015;71:2834-45.

21. Lorig KR, Holman H. Self-Management education: history, definition, outcomes, and mechanisms. Ann Behav Med 2003;26:1-7

22. Ellis J, Boger E, Latter S, et al. Conceptualisation of the 'good' self-manager: A qualitative investigation of stakeholder views on the self-management of long-term health conditions. Soc Sci Med 2017;176:25-33.

23. Liddy C, Blazkho V, Mill K. Challenges of self-management when living with multiple chronic conditions: systematic review of the qualitative literature. Can Fam Physician 2014:60:1123-33.

24. Murphy K, Chuma T, Mathews $C$, et al. A qualitative study of the experiences of care and motivation for effective self-management among diabetic and hypertensive patients attending public sector primary health care services in South Africa. BMC Health Serv Res 2015;15:303

25. Powers MA, Bardsley J, Cypress M, et al. Diabetes self-management education and support in type 2 diabetes: a joint position statement of the American diabetes association, the American association of diabetes educators, and the Academy of nutrition and dietetics. $J$ Acad Nutr Diet 2017;115.

26. Guo P, Harris R. The effectiveness and experience of selfmanagement following acute coronary syndrome: a review of the literature. Int J Nurs Stud 2016;61:29-51.

27. Wu C-JJ, Chang AM, Courtney M, et al. Using user-friendly telecommunications to improve cardiac and diabetes selfmanagement programme: a pilot study. J Eval Clin Pract 2012;18:695-7.

28. Wu C-JJ, Chang AM, Courtney M, et al. Peer supporters for cardiac patients with diabetes: a randomized controlled trial. Int Nurs Rev 2012;59:345-52.

29. CJJ W, Chang AM, Courtney M, et al. Development and pilot test of a peer-support based Cardiac-Diabetes self-management program: a study protocol. BMC Health Serv Res 2011;11.

30. Diabetes Association of Chinese Medical Association. Guideline of prevention and treatment for type 2 diabetes in China (2013 edition). Chinese Journal of Diabetes Mellitus 2014;30:893-942.

31. Fetters MD, Curry LA, Creswell JW. Achieving integration in mixed methods designs-principles and practices. Health Serv Res 2013;48:2134-56.

32. Creswell JW, Plano Clark VL. Designing and conducting mixed methods research. third. Los Angeles, USA: SAGE, 2018.

33. Liu X-L, Wu C-JJ, Willis $\mathrm{K}$, et al. The impact of inpatient education on self-management for patients with acute coronary syndrome and type 2 diabetes mellitus: a cross-sectional study in China. Health Educ Res 2018;33:389-401.
34. Bazeley P, Jackson K. Qualitative data analysis with NVivo. London: Sage, 2013.

35. World Medical Association. World Medical association Declaration of Helsinki: ethical principles for medical research involving human subjects. JAMA 2014;310:2191-4.

36. Persell SD, Keating NL, Landrum MB, et al. Relationship of diabetes-specific knowledge to self-management activities, ambulatory preventive care, and metabolic outcomes. Prev Med 2004;39:746-52

37. Riegel B, McKinley S, Moser DK, et al. Psychometric evaluation of the acute coronary syndrome (ACS) response index. Res Nurs Health 2007:30:584-94

38. Vivienne Wu S-F, Courtney M, Edwards H, et al. Development and validation of the Chinese version of the diabetes management selfefficacy scale. Int J Nurs Stud 2008;45:534-42.

39. Abdo NM, Mohamed ME. Effectiveness of health education program for type 2 diabetes mellitus patients attending zagazig university diabetes clinic, Egypt. J Egypt Public Health Assoc 2010;85:113-30.

40. Geboers B, Reijneveld SA, Jansen CJM, et al. Health literacy is associated with health behaviors and social factors among older adults: results from the lifelines cohort study. $J$ Health Commun 2016;21:45-53.

41. Wynn Nyunt S, Howteerakul N, Suwannapong N, et al. Self-Efficacy, self-care behaviors and glycemic control among type-2 diabetes patients attending two private clinics in Yangon, Myanmar. Southeast Asian J Trop Med Public Health 2010;41:943-51.

42. Vaismoradi M, Turunen $\mathrm{H}$, Bondas $\mathrm{T}$. Content analysis and thematic analysis: implications for conducting a qualitative descriptive study. Nurs Health Sci 2013;15:398-405.

43. Castro FG, Kellison JG, Boyd SJ, et al. A methodology for conducting integrative mixed methods research and data analyses. $J$ Mix Methods Res 2010;4:342-60.

44. International QSR. NVivo qualitative data analysis software | QSR international, 2017. Available: http://www.qsinternational.com/ [Accessed 22 Aug 2017].

45. Fielding NG. Triangulation and mixed methods designs: data integration with new research technologies. J Mix Methods Res 2012;6:124-36

46. Creswell JW, Klassen AC, Plano Clark VL, et al. Best practices for mixed methods research in the health sciences. Bethesda (Maryland: National Institutes of Health, 2011: 2094-103.

47. Welch A, Jirojwong $S$, et al, Sampling in qualitative research. Research methods in nursing and midwifery: pathways to evidence-based practice. Oxford: Oxford University Press, 2011: 87-97.

48. Brett J, Staniszewska S, Mockford C, et al. Mapping the impact of patient and public involvement on health and social care research: a systematic review. Health Expect 2014;17:637-50.

49. International Diabetes Federation Guideline Development Group. Global guideline for type 2 diabetes. Diabetes Res Clin Pract 2014;104:1-52

50. Lai DWL, Surood S. Chinese health beliefs of older Chinese in Canada. J Aging Health 2009;21:38-62.

51. Kwok C, Sullivan G. Health seeking behaviours among ChineseAustralian women: implications for health promotion programmes. Health 2007;11:401-15.

52. Hersi A, Al-Habib K, Al-Faleh $\mathrm{H}$, et al. Gender inequality in the clinical outcomes of equally treated acute coronary syndrome patients in Saudi Arabia. Ann Saudi Med 2013;33:339-46.

53. Cabrerizo-García JL, Pérez-Calvo Jl, Zalba-Etayo B. Influence of gender on prognosis of acute coronary syndromes. Rev Port Cardiol 2015;34:43-50.

54. Pancholy SB, Shantha GPS, Patel T, et al. Sex differences in short-term and long-term all-cause mortality among patients with ST-segment elevation myocardial infarction treated by primary percutaneous intervention: a meta-analysis. JAMA Intern Med 2014:174:1822-30

55. Berenguera A, Molló-Inesta Àngels, Mata-Cases M, et al. Understanding the physical, social, and emotional experiences of people with uncontrolled type 2 diabetes: a qualitative study. Patient Prefer Adherence 2016;10:2323-32.

56. Karimy M, Araban M, Zareban I, et al. Determinants of adherence to self-care behavior among women with type 2 diabetes: an explanation based on health belief model. Med J Islam Repub Iran 2016;30.

57. Martyn-Nemeth PA, Vitale GA, Cowger DR. A culturally focused exercise program in Hispanic adults with type 2 diabetes: a pilot study. Diabetes Educ 2010;36:258-67.

58. Murrock CJ, Higgins PA, Killion C. Dance and peer support to improve diabetes outcomes in African American women. Diabetes Educ 2009;35:995-1003. 
59. Gomes Neto M, Menezes MA, Oliveira Carvalho V. Dance therapy in patients with chronic heart failure: a systematic review and a metaanalysis. Clin Rehabil 2014;28:1172-9.

60. Saw A, Paterniti D, Fung L-C, et al. Social environmental influences on smoking and cessation: qualitative perspectives among Chinesespeaking smokers and nonsmokers in California. J Immigr Minor Health 2016:19:1-8.

61. Jiang S, Beaudoin CE. Smoking prevention in China: a content analysis of an anti-smoking social media campaign. $J$ Health Commun 2016;21:755-64.

62. Nicoll R, Zhao Y, Ibrahimi P, et al. Diabetes and hypertension consistently predict the presence and extent of coronary artery calcification in symptomatic patients: a systematic review and metaanalysis. Int J Mol Sci 2016;17. doi:10.3390/ijms17091481. [Epub ahead of print: 06 Sep 2016].
63. Baig AA, Benitez A, Quinn MT, et al. Family interventions to improve diabetes outcomes for adults. Ann N Y Acad Sci 2015;1353:89-112.

64. MC-T T. An Oriental understanding of health. Tzu Chi Medical Journal;24.

65. Powers MA, Bardsley J, Cypress M, et al. Diabetes self-management education and support in type 2 diabetes. Diabetes Educ 2017; 43:40-53.

66. Johnson RB, Christensen L. Validity of research results in quantitative, qualitative and mixed research. In: Johnson RB, Christensen L, eds. Educational research quantitative, qualitative, and mixed approaches. California: United States of America: SAGE, 2017: 306-10.

67. Onwuegbuzie AJ, Johnson RB. The validity issue in mixed research. Research in the Schools 2006;13:48-63. 